Number of tables: 3 tables in the manuscript and 2 tables in Supplementary Materials

Dimensions of religiosity: The effects of attendance at religious services and religious faith

on discontinuity in substance use

Hei Wan Mak, MSc

Department of Sociology, University of Cambridge, 16 Mill Lane, Cambridge, CB2 1SB

Tel: 01223334520

Email: hwm24@cam.ac.uk or hei.mak@ucl.ac.uk 


\title{
Dimensions of religiosity: The effects of attendance at religious services and religious faith on discontinuity in substance use
}

\begin{abstract}
Background: The existing literature has shown that religion plays an important role in the use of cigarettes, alcohol, and drugs. Objectives: This study examines and compares the effects of the two widely used dimensions of religiosity, religious behaviour measured by attendance at religious services and religious devotion by the importance of religious faith, on cigarette, alcohol and drug non-use in adulthood. Methods: Data from Waves 1, 3 and 4 data were employed for analysis. The sample was restricted to those who reported having used the substance in Wave 3. The number of core sample sizes varied depending on the type of substance, $N=666-1045$. Logistic regression and propensity score matching (PSM) methods were used. Results: Results showed that church attendance frequency was significantly and positively associated with any kind of substance non-use in the past 30 days, whereas religious faith predicted the discontinuity of alcohol use only. After controlling for the observables and confounding bias in the PSM models, results remained statistically significant. Conclusions: This study suggests that social and instrumental support offered by churches may help people abstain from substance use. Health professionals could consider establishing partnerships with religious communities to support substance users.
\end{abstract}




\section{INTRODUCTION}

Alcohol, tobacco, and illegal drug use are estimated to cost the US around $\$ 740$ billion each year, in which drinking-related illness accounts for almost $33 \%$ of healthcare spending (NIDA,

2017). Substance use cessation has been found to have significant improvement in health in comparison to people who continue using substances, including better respiratory symptoms and health-related quality of life (Doll, 2004; Holmes et al., 2016; Tillmann \& Silcock, 1997; Volkow et al., 2014).

There is consistent evidence that religiosity is protective against substance use. Existing literature has shown that individuals with higher levels of religiosity are more likely to be abstinent from substances, to reduce the amount of usage, to have higher rates of cessation, and are less likely to experience relapse following a period of cessation (Brown et al., 2001; Brown et al., 2014; Edlund et al., 2010; Gossop et al., 2008; Kendler et al., 2003; Koenig \& Vaillant, 2009; Luczak et al., 2003; Nakash et al., 2016; Whooley et al., 2002; Wills et al., 2003). The association between religion and substance use has been increasingly recognised; some substance abuse treatment programmes in the US offer religious services (Davis, 2014; Gonzales et al., 2007). Most world-wide addiction centres, such as the Alcoholics Anonymous, provide the 12-Step spiritually-based programme to support people to achieve and maintain abstinence from substance abuse.

One major issue in religion research is the measurement of religiosity. In research, religiosity is a latent construct that cannot be observed or directly measured but can be inferred from other observed variables (Miller \& Thoresen, 2003). Two dimensions of religiosity are often used as proxies for measuring levels of religiosity: religious behaviours indicated by the frequency of church attendance and religious faith assessed by individuals' ratings of the importance of religious faith or religious belief to them personally. Studies have found both dimensions to be 
a protective factor with regard to substance use, though there is disagreement about their relative importance. Rasic et al. (2011) and Edlund et al. (2010) demonstrated that both strong religious faith and frequent church attendance were related to low alcohol and drug use, although Edlund et al. (2010) found that the odds ratios were larger in relation to church attendance. In contrast, Kulis et al. (2012) showed that there was no effect of attendance at religious services on any substance use outcomes. However, they found that strong religious beliefs, a scale that reflected the importance to respondents of following traditional Indian or Christian beliefs, was associated with lower alcohol and cigarette consumption. This may be explained by the links provided by the Indian and Christian beliefs to cultural heritage, established values systems and traditions, which may, in turn, protect against substance use (Kulis et al., 2012). The conflicting results suggest that it remains unclear whether the changes in substance use behaviours are a result of religious behaviour or religious devotion. Investigating the various effects of these two dimensions of religiosity is important as this could affect how the collaboration between healthcare services and religious communities should be promoted and delivered.

A challenge when researching the effects of the two dimensions of religiosity is that religiosity is socially patterned. Demographic differences in the levels of religiosity may lead to over- or underestimation of the potential effect religiosity may have on the discontinuity in substance use. Therefore, this study used propensity score matching (PSM) techniques to control for selection on observables and to remove the effects of any potential factors that might possibly influence individuals' levels of religiosity and/or the probability of the discontinuity in substance use (Rosenbaum \& Rubin, 1983, 1984, 1985). 


\section{DATA AND METHOD}

\section{Data}

Add Health is a US longitudinal data set that follows a nationally representative sample of adolescents in school grades 7-12 in 1994/95 to adulthood (Harris et al., 2009). Within the sample, around $85 \%$ had a parent who completed the questionnaire in Wave 1. Data were collected at four points through adolescence to the transition to adulthood; the subsequent interviews were conducted in 1996, 2001/02, and 2008 when sample members were aged 2532. The data cover a wide range of adolescent health and health behaviours, and multiple contexts of adolescent life such as religiosity, parents' self-reported substance use, and socioeconomic background.

The main analyses used Wave 1, 3, and 4 from the public-use in-house data sets, which consist of a random selection of the original data. All follow-up interviews were with original Wave 1 respondents who were eligible for the interviews. The attrition rate was approximately $12 \%$ between waves; respondents who were non-White, started using substances at earlier ages, and whose parents had low educational levels were more likely to drop out by Wave 4 . The sample was restricted to respondents who were aged between 13 and 18 at the time of the first interview and those who reported having (a) used at least one cigarette per day, (b) consumed at least one alcohol drink per day or consumed 3 or more drinks in one occasion at least 2 times a month (based on the definitions of "moderate alcohol consumption" and "drinking at low risk" provided by the NIAAA, 2019), (c) used marijuana at least once, or (d) used any illicit drugs (including cocaine, crystal meth, marijuana and other types of illegal drugs) at least once, since 1995 and in the past 30 days in the Wave 3 interview (aged 18-25). The number of core sample size varied depending on the type of substance $(N=666-1045)$. 


\section{MEASURES}

\section{Substance non-use in the past 30 days}

Four variables indicating the absence of substance use (i.e. cigarette, alcohol, marijuana, or any illicit drugs) at Wave 4 were generated when respondents reported no substance use in the past 30 days. Given the analysis was restricted to respondents who reported of having used the substance in the past month at Wave 3, and given these respondents had also reported of using the substance since 1995, the "non-use" category at Wave 4 should conclusively demonstrate a change in use level from Wave 3 to Wave 4.

\section{Church attendance and religious faith}

Church attendance frequency and importance of religion were measured at Wave 4 . For church attendance frequency, respondents were asked how often they had attended church, synagogue, temple, mosque, or religious services in the past year. A binary variable was generated in which 1 denotes respondents who attended once a week or more and 0 denotes otherwise. Religious faith was assessed by individuals' ratings of the importance of religious faith. It was dichotomised with "very important" and "more important than anything else" combined as one category and "somewhat important" and "not important" as the other.

\section{Control variables}

PSM models incorporated possible confounding variables based on previous empirical research that might be associated with both the religiosity dimensions and absence of substance use or with the absence of substance use only (Brookhart et al., 2006; Caliendo \& Kopeinig, 2008; Rubin, 2001). The control variables measured in Wave 1 included sample members' age, gender, ethnicity, household type, levels of substance use in the past 30 days (cigarette, alcohol, marijuana, or any illicit drugs), parents' educational level, maternal cigarette and/or alcohol 
consumption, and parents' self-reported church attendance frequency (included only in the model estimating the effect of church attendance frequency) and religious faith (only in the model estimating the effect of religious faith) (Kliewer \& Murrelle, 2007). Four continuous variables indicating the levels of substance use in the past 30 days measured in Wave 3 were controlled, since various levels of use might affect the probability of non-use later in life. The analysis also controlled for Wave 4 variables: educational level, marital status, presence of child(ren) (Bachman et al., 2002), respondents' living area (Martino et al., 2008), and a continuous indicator of age at first substance use, which was derived from responses to all four waves of the survey (Breslau \& Peterson, 1996).

\section{Statistics}

In this study, both logistic regression and PSM estimation methods were used to estimate the relationships between church attendance frequency and religious faith and the rates of substance non-use in the past 30 days at Wave 4.

PSM created two groups from a sample, a treatment (i.e. respondents who had high levels of church attendance frequency or religious faith) and a control group (i.e. respondents who had low levels of church attendance frequency or religious faith). It then matched each respondent with high levels of attendance or religious faith with one or more than one respondents who had low levels of attendance or religious faith based on propensity scores. This method effectively creates an experimental study of an observational data set by allowing the matched respondents to be identical in every observed variable (Rosenbaum \& Rubin, 1983). Epanechnikov kernel matching with 0.05 bandwidths was applied to calculate the average treatment effect on the treated (ATT). ATT is the difference between the average outcome measure for respondents who had high levels of church attendance/religious faith and the average outcome measure for the sample group under the hypothetic situation that they had 
low levels of attendance/religious faith. Therefore, the difference between the treatment and control groups should not be influenced by the observed covariates. PSM is also able to determine how well the density distributions between the treatment and control groups overlap, that is, the quality of matching. High quality of matching is defined when the average covariate unbalancing percentage is less than $10 \%$ (Morgan, 2018). Standard errors were computed by bootstrapping with 1000 replications. Missing data were handled with listwise deletion. To check the robustness of the results, all analyses were replicated using another PSM technique which involved matching one treatment unit with two control units that had the closest propensity score (i.e. nearest-neighbour matching); standard errors were computed using Abadie-Imbens formulas.

Results for all PSM models demonstrated high standard matching; the quality of matching was higher with the kernel matching method.

\section{RESULTS}

\section{Demographic backgrounds}

In the sample, female and non-White respondents were likely to have higher levels of church attendance frequency and religious faith. Religious respondents (those who had high levels of attendance or religious faith) tended to have parents who consumed less cigarettes or alcohol, and who were more likely to be frequent church attendees and/or had higher levels of religious faith. They were also likely to postpone the age at which they had their first substance use, to be married, to have child(ren), and to report not having used substances in the past month in Wave 4. Demographic statistics of alcohol use by the two religious dimensions are shown in Supplementary Tables S1 and S2; statistics were similar across different samples using various substances (not shown). 
The descriptive statistics indicate that respondents with high levels of church attendance frequency or religious faith tended to possess characteristics (e.g. low levels of maternal alcohol consumption) that favoured more positive outcomes. It then became unclear whether it was the religion, either church attendance or religious faith, that was driving substance use discontinuity or whether it was the shared characteristics that affected the discontinuity (i.e. a confounding bias).

\section{Church attendance and religious faith and substance non-use using PSM}

\section{(Table 1)}

Tables 1 and 2 present results from four different models: (a) unadjusted coefficients (log-odds) from logistic regression models; (b) adjusted coefficients from logistic regression models; (c) ATTs from PSM models using the kernel matching method; and (d) ATTs from PSM models using the nearest-neighbour matching method. Any differences found between the logistic regression and PSM results would give an indication of the magnitude of the confounding effects.

Table 1 shows that church attendance frequency was significantly associated with all types of substance non-use, suggesting that respondents with a high level of church attendance frequency were more likely to have been abstinent from the substance for at least a month period. In adjusted logistic models, the log-odds for cigarette, alcohol, marijuana, and any illicit drug non-use were $0.94(\mathrm{p}<0.01), 1.43(\mathrm{p}<0.001), 1.28(\mathrm{p}<0.01)$, and $1.40(\mathrm{p}<0.01)$, respectively. Results obtained from the PSM models indicate that the effect of church attendance dropped sharply after controlling for the observed variables and confounding bias. In kernel matching models, the ATTs for cigarette, alcohol, marijuana, and any illicit drug nonuse were $0.20(\mathrm{p}<0.001), 0.17(\mathrm{p}<0.01), 0.23(\mathrm{p}<0.01)$, and $0.25(\mathrm{p}<0.001)$; this indicates that a higher level of church attendance frequency was associated with an increase of 19\%-29\% (i.e. 
exponentiating the log-odds and subtracting it from 1) in the likelihood of non-use in the past 30 days. Although the associations between church attendance and substance non-use were weaker in the PSM models, all estimates remained statistically significant. Importantly, these findings could not be explained by the differences in terms of demographic backgrounds, religious upbringing, or previous levels of substance use between groups given that the analyses matched participants on these factors. These findings provide a solid evidence base for the association between church attendance and any kind of substance non-use.

(Table 2)

With respect to another dimension of religiosity, Table 2 shows that alcohol non-use in the past 30 days was positively related to religious faith. In the adjusted logistic model, the log-odds for alcohol non-use was $0.48(\mathrm{p}<0.05)$, meaning that a higher level of religious faith was related to an increase of $62 \%$ in the rate of absence of alcohol consumption. Again, the effect of religious faith reduced substantially after adjusting for the covariates and confounding bias. In the kernel model, the ATT for alcohol non-use was $0.06(\mathrm{p}<0.05)$, indicating that a higher level of religious faith was associated with a $6 \%$ increase in the likelihood of alcohol non-use. This suggests that not taking into account the confounding bias might have overestimated the effect of religious faith on alcohol non-use. No significant association was found between religious faith and cigarette or drug non-use in the past 30 days.

Post hoc tests were carried out using the $z$-statistics to compare the ATTs of church attendance and religious faith across models (Clogg et al., 1995; Paternoster et al., 1998). Results demonstrate that the ATTs of the two religiosity dimensions were significantly different across models (i.e. when the z-value is greater than 1.96 or lower than -1.96); the z-values were 3.05, 2.13, 2.82, and 3.11 for cigarette, alcohol, marijuana, and any illicit drug, respectively. This 
post hoc tests imply that the effect of church attendance might be somewhat more pronounced than religious faith.

\section{Sensitivity analysis}

(Table 3)

All analyses were repeated with various alternative specifications as sensitivity checks; results are presented in Table 3. Panel 1 shows ATT estimates from analyses where the sample was restricted to those who indicated problematic substance use at Wave 3. Problematic substance users were defined as the top $20 \%$ of cigarette, marijuana, or any illicit drug users, or respondents who consumed 5 or more alcohol drinks on the same occasion more than 2 times in a month (based on the "binge drinking" definition provided by the NIAAA, 2019). Results show that the positive association between church attendance frequency and substance non-use in the past month remained, although the effect of church attendance on the discontinuities of cigarette, alcohol, and marijuana use reduced to at least the $10 \%$ significance level and some PSM matching models failed to achieve successful matching. No significant relationship was found between religious faith and substance non-use among respondents with previous problematic use.

Panel 2 partially addresses the implicit assumption that substance non-use was influenced by the level of religiosity (either church attendance or religious faith) rather than the level of religiosity responding to the non-use; it is possible that the relationship was bidirectional. In the second sensitivity checks, the analyses were based on a sample of those who had low levels of religiosity previously. Results show that respondents who became frequent church attendees or who increased their level of religious faith also had a higher probability of substance nonuse in Wave 4. It is, however, important to note that this analysis was unable to identify the causality of the relationship between religiosity and substance non-use; it is possible that the 
absence of use might have happened before respondents became frequent attendees or increased their faith in religious belief. However, what this table shows is the change of substance use behaviour when respondents reported having increased the frequency of church attendance or the level of religious faith.

The final sensitivity check explored whether the effects of the two religious dimensions extended to a longer period of absence of use. Similar to the main analyses, the level of church attendance frequency was positively correlated with alcohol and drug non-use (please note that cigarette use in the past 12 months was not asked in the Wave 4 interview), whereas religious faith was associated with alcohol non-use. These findings confirm the results found in the main analyses that church attendance, and possibly religious faith, may help support substance users to achieve abstinence.

\section{DISCUSSION}

This paper compares the effects of two different religious dimensions, church attendance (religious behaviours) and religious faith (religious devotion), on substance non-use, and attempts to disentangle the effects of these two dimensions from other observable factors via the PSM methods. The results of the present study have two important contributions. First, church attendance frequency and religious faith have different relationships with substance non-use. Church attendance has a larger and greater effect for all outcomes compared to religious faith. This finding remained for respondents who had a history of problematic use or those who had low levels of religiosity previously, suggesting that church attendance may be effective in guarding against further development of substance use among respondents who were already experiencing such behaviours, and that substance use behaviour changes with the change of religiosity levels, particularly church attendance. While this finding may be at odds with the study of Longest and Vaisey (2008) who found that religious salience was more 
protective against adolescent marijuana use than religious involvement, both the present study and Longest and Vaisey's study suggest that religious dimensions may have various effects on different types of behaviour. It is possible that, for example, religious faith and devotion are more effective in preventing initiation, whereas religious participation that involves direct exposure to religious institutions and church members might help promote abstention. Miller and Gur's (2002) parallel study supports this by demonstrating that religious faith and devotion were more effective in reducing the risk of lifetime sexual activity outside a relationship, whereas a high level of church attendance frequency was positively associated with the use of birth control.

The second contribution is that a large amount of heterogeneity was found in the relationship between the two religious dimensions and substance non-use. The effects of the two dimensions diminished substantially after controlling for the observables and confounding bias in the PSM models; this suggests, not taking into account the confounding bias, the effects of religious behaviour and devotion were likely to have been overestimated. Nevertheless, the current study found that church attendance and religious faith remained significant in the PSM models.

Multiple factors can help explain the beneficial effect of church attendance. Firstly, a high level of church attendance may lead to less time spent on other risk activities, including substance use. More importantly, some religious communities may organise events to educate participants about the risks and consequences of substance use. They may also provide emotional and instrumental supports for those who have already engaged in substance use by offering counselling sessions, educational workshops (e.g. discussions of consequences of substance use), coping resources and referral services (Koenig, 2012). This would be especially critical for heavy substance users, who may be more likely to suffer withdrawal symptoms (e.g. 
sleeping difficulties and anxiety) and thus have lower success rates of abstinence from substances than light or regular users. Secondly, the social support provided by churches may influence the association between religious involvement and the likelihood of using substances (CASA, 2011; Koenig, 2012). In particular, religion connects individuals to communities or social networks that have lower rates of substance use. Thirdly, frequent church attendees are found to have better mental health (Koenig, 2005; Koenig et al., 2007), which is associated with lower levels of substance use (Gilvarry, 2000; Stone et al., 2012; von Sydow et al., 2002; Wills et al., 2003). Furthermore, churches could be an alternative and attractive option for users to achieve abstinence, especially when many cessation programs are expensive and are associated with a health-related stigma that might make users reluctant to join (Luoma et al., 2007).

Although this study found that church attendance has a larger effect across various types of substance non-use, religious faith is significantly related to alcohol non-use. This result is in line with Edlund et al.'s study (2010), which demonstrated that respondents who reported religion was important were less likely to consume alcohol and experience alcohol abuse/dependence among those who drank. Unlike cigarette and drug use, light and low-risk alcohol use is more socially accepted; some religions even provide wine during Mass. Previous studies have also suggested that it is a common route for heavy drinkers to return to light drinking, instead of complete abstinence (Schulenberg et al., 2017; Sobell et al., 2000). However, what this study found suggests that respondents who wished to stop drinking might need outside assistance to achieve alcohol non-use, and that both social reinforcement within religious institutions and the commitment to the religion might be important to alcohol users' achievement of abstinence. A good example to demonstrate the significant role of religious faith is the study of Gossop et al. (2008). Gossop et al. (2018) found that frequent attendees in treatment centres, which use the 12-Step approach to support clients with drug and alcohol 
problems via an emphasis on religious meaning and righteousness, were more likely to be abstinent from alcohol use compared to non-attendees and infrequent attendees.

Although the current study has strengths and expands the literature in important ways, there are some limitations that need to be considered. First, this study only considered two widely used dimensions of religiosity; future study is needed to identify the effects of other dimensions (e.g. religious exclusivity) of religiosity on substance non-use. Further work is also required to investigate whether the significance of religious behaviour and devotion with respect to substance non-use varies across cultures and religious affiliations; different religious institutions may have various attitudes toward substances, especially alcohol. Second, the cutoff point for dividing the sample into the "treatment" and the "control" groups (e.g. frequent and infrequent church attendees) may be arbitrary, further studies might like to consider in more detail the thresholds for religious dimensions. Third, while PSM controls for observed factors, the unobserved heterogeneity might remain an issue (e.g. the motivation to quit using substances and the reasons for attending churches). However, the richness of the data set had allowed matching to a high standard, meaning that any remaining unobserved heterogeneity should have been minimised. Furthermore, due to data limitation, the study was unable to estimate whether respondents would return to substances or relapse after reporting no use in the last interview; nonetheless, a one-month period of non-use was found to have had some health benefits, including a reduction in wound-healing complications (Wong et al., 2012). Another limitation was that, results might involve a self-report bias since some respondents might have underreported their substance use. However, there is evidence showing that selfreported substance use behaviours, including heavy consumption, was reasonably valid (Brown et al., 1992; Del Boca \& Darkes, 2003). Finally, this study handled missing data with listwise deletion, it is plausible that there might be potential attrition bias in the sample. Future studies 
might like to consider using advanced techniques (such as multiple imputations) to handle missing data.

\section{CONCLUSION}

This study provided insights into the relationship between religiosity and substance non-use. Two dimensions of religiosity were examined, religious behaviour indicated by church attendance frequency and religious faith measured by the importance of religious faith. Systematic steps were taken to separately investigate their effects using logistic regressions and the PSM technique. Results showed that religious behaviour had a greater effect than religious devotion to protect against the use of substances. It may therefore be beneficial for health professionals and substance use treatment programmes to consider collaborating with religious communities to provide preventive health and social services to people with substance use problems. By increasing partnerships between religious groups and health professionals, it is likely that a wider population, especially individuals with low incomes, could have access to healthcare and thus potentially reduce health inequality in society.

\section{References}

Bachman, J., O'Malley, P., Schulenberg, J., Johnston, J., Bryant, A., \& Merline, A. (2002). The decline of substance use in young adulthood: changes in social activities, roles, and beliefs. Mahwah, NJ, US: Lawrence Erlbaum Associates Publishers.

Breslau, N., \& Peterson, E.L. (1996). Smoking cessation in young adults: age at initiation of cigarette smoking and other suspected influences. American Journal of Public Health, 86(2), 214-220. 
Brookhart, M.A., Schneeweiss, S., Rothman, K.J., Glynn, R.J., Avorn, J., \& Sturmer, T. (2006). Variable selection for propensity score models. American Journal of Epidemiology, 163(12), 1149-1156.

Brown, T.L., Parks, G.S., Zimmerman, R.S., \& Phillips, C.M. (2001). The role of religion in predicting adolescent alcohol use and problem drinking. Journal of Studies on Alcohol and Drugs, 62(5), 696-705.

Brown, J., Kranzler, H.R., \& Del, B.F.K. (1992). Self reports by alcohol and drug abuse inpatients: factors affecting reliability and validity. British Journal of Addiction, 87(7), 1013-24.

Brown, Q.L., Linton, S.L., Harrell, P.T., Mancha, B.E., Alexandre, P.K., Chen, K.F., \& Easton, W.W. (2014). The influence of religious attendance on smoking among black men. Substsance Use \& Misuse, 49(11), 1392-1399.

Caliendo, M., \& Kopeinig, S. (2008). Some practical guidance for the implementation of propensity score matching. Journal of Economics Surveys, 485(1), 1-29.

Clogg, C.C., Petkova, E., \& Haritou, A. (1995). Statistical methods for comparing regression coefficients between models. American Journal of Sociology, 100(5), 12611293.

Davis, M.T. (2014). Religious and non-religious components in substance abuse treatment: a comparative analysis of faith-based and secular interventions. Journal of Social Work, 14(3), 243-259.

Del Boca, F.K., Darkes, J. (2003). The validity of self-reports of alcohol consumption: state of the science and challenges for research. Addiction, 98, 1-12. 
Doll, R. (2004) Mortality in relation to smoking: 50 years' observations on male British doctors. British Medical Journal, 328, 1519.

Edlund, M.J., Harris, K.M., Koenig, H.G., Han, X., Sullivan, G., Mattox, R., \& Tang, L. (2010). Religiosity and decreased risk of substance use disorders: is the effect mediated by social support or mental health status? Social Psychiatry \& Psychiatric Epidemiology, 45(8), 827-836.

Gilvarry, E. (2000). Substance abuse in young people. Journal of Child Psychology \& Psychiatry, 41(1), 55-80.

Gonzales, D., Redtomahawk, D., Pizacani, B., Bjornson, W.G., Spradley, J., Allen, E., \& Lees, P. (2007). Support for spirituality in smoking cessation: results of pilot survey. Nicotine \& Tobacco Research, 9(2), 299-303.

Gossop, M., Stewart, D., \& Marsden, J. (2008). Attendance at Narcotics Anonymous and Alcoholics Anonymous meetings, frequency of attendance and substance use outcomes after residential treatment for drug dependence: a 5-year follow-up study. Addiction, 103(1), $119-125$

Harris, K.M., Halpern, C.T., Whitsel, E., Hussey, J., Tabor, J., Entzel, P., \& Udry, J.R. (2009). The National Longitudinal Study of Adolescent to Adult Health: Research Design. Retrieved from: http://www.cpc.unc.edu/projects/addhealth/design.

Holmes, J., Angus, C., Meier, P., \& Brennan, A. (2016). Potential Years OfLife Lost (PYLL) Due To Alcohol Consumption In The UK. An Addendum To:Mortality And Morbidity Risks From Alcohol Consumption In The UK: Analyses Using The Sheffield Alcohol Policy Model (V.2.7) To Inform The UK Chief Medical Officers' Review Of The UK Lower Risk Drinking Guidelines, Final Report, 1-13. Availalble from: 
https://www.shef.ac.uk/polopoly_fs/1.538671!/file/Drinking_Guidelines_Final_Report_P ublished.pdf.

Kamieneski, R., Brown, C. M., Mitchell, C., Perrin, K. M., \& Dindial, K. (2000). Health benefits achieved through the Seventh-Day Adventist Wellness Challenge program. Alternative Therapies in Health and Medicine, 6(6), 65-69.

Kendler, K.S., Liu, Z.Q., Gardner, C.O., McCullough, M.E., Larson, D., \& Prescott, C.A. (2003). Dimensions of religiosity ad their relationship to lifetime psychiatric and substance use disorders. American Journal of Psychiatry, 160(3), 496-503.

Kliewer, W., \& Murrelle, L. (2007). Risk and protective factors for adolescent substnce use: Findings from a study in selected Central American countries. Journal of Adolescent Health, 40(5), 448-455.

Koenig, H.G. (2005). Faith And Mental Health: Religious Resources For Healing. Templeton Foundation Press, Philadeplhoa.

Koenig, H. G. (2012). Religion, spirituality, and health: The research and clinical implications. ISRN Psychiatry, 2012, 1-33.

Koenig, H.G., McCullough, M.E., \& Larson, D.B. (2001). Handbook Of Religion And Health. Oxford University Press, New York.

Koenig, L.B., Vaillant, G.E. (2009). A prospective study of church attendance and health over the lifespan. Health Psychology, 28(1), 117-124.

Kulis, S., Hodge, D.R., Ayers, S.L., Brown, E.F., \& Marsiglia, F.F. (2012). Spirituality and religion: intertwined protective factors for substance use among urban American Indian youth. The American Journal of Drug and Alcohol Abuse, 38(5), 444-449. 
Lasser, K., Boyd, J.W., Woolhandler, S., Himmelstein, D.U., McCormick, D., \& Bor, D.H. (2000). Smoking and mental illness: a population-based prevalence study. JAMA, 284(20), 2606-2610.

Longest, K. C., \& Vaisey, S. (2008). Control or Conviction: religion and adolescent initiation of marijuana use. Journal of Drug Issues, 38(3), 689-715.

Luczak, S.E., Corbett, K., Oh, C., Carr, L.G., \& Wall, T.L. (2003). Religious influences on heavy episodic dcrinking in Chinese-American and Korean-American College Students. Journal of Studies on Alcohol, 64(4), 467-471.

Luoma, J.B., Twohig, M.P., Waltz, T., Hayes, S.C., Roget, N., Pailla, M., \& Fisher, G. (2007). An investigation of stigma in individuals receiving treatment for substance abuse. Addictive Behaviors, 32(7), 1331-1346.

Martino, S.C., Ellickson, P.L., \& McCaffrey, D.F. (2008). Developmental trajectories of substance use from early to late adolescence: a comparison of rural and urban youth. Journal of studies on Alcohol and Drugs, 69(3), 430-440.

Miller, L., \& Gur, M. (2002). Religiousness and sexual responsibility in adolescent girls. Journal of Adolescent Health, 31(5), 401-406.

Miller, W. R., \& Thoresen, C. E. (2003). Spirituality, religion, and health. An emerging research field. The American Psychologist, 58(1), 24-35.

Nakash, O., Nagar, M., Barker, Y., \& Lotan, D. (2016). The association between religiosity and alcohol use: the mediating role of meaning in life and media exposure. Mental Health Religion \& Culture, 19(6), 574-586.

CASA (2011). So help me God: Substance abuse, religion and spirituality. National Center 
on Addiction and Substance Abuse at Columbia University, New York.

NIDA (2017). Trends \& Statistics.Narional Institute on Drug Abuse. Retrieved from: https://www.drugabuse.gov/related-topics/trends-statistics.

NIAAA (2019). Drinking Levels Defined. National Institute on Alcohol Abuse and Alcoholism. Retrieved from: https://www.niaaa.nih.gov/alcohol-health/overview-alcoholconsumption/moderate-binge-drinking.

Paternoster, R., Brame, R., \& Piquero, A. (1998). Using the correct statistical test for the equality of regression coefficients. Criminology, 36(4), 859-866.

Rasic, D., Kisely, S., \& Langille, D.B. (2011). Protective associations of importance of religion and frequency of service attendance with depression risk, suicidal behaviours and substance use in adolescents in Nova Scotia, Canada . Journal of Affective Disorders, 132(3), 389-395.

Rosenbaum, P.R., \& Rubin, D.B. (1983). The central role of the propensity score in observational studies for causal effects. Biometrika, 70(1), 41-55.

Rosenbaum, P.R., \& Rubin, D.B. (1984). Reducing bias in observational studies using subclassification on the propensity score. Jourmal of the American Statistical Association, 79(387), 516-524.

Rosenbaum, P.R., \& Rubin, D.B. (1985). Constructing a control group using multivariate matched sampling methods that incorporate the propensity score. The American Statistician, 39(1), 33-38.

Rubin, D.B. (2001). Using propensity scores to help design observational studies: application to the tobacco litigation. Health Services \& Outcomes Research Methodology, 
2(3-4), 169-188.

Schulenberg, J.E., Johnston, L.D., O’Malley, P.M., Bachman, J.G., Miech, R.A., \& Patrick, M.E. (2017). Monitoring the Future: National Survey Results on Drug Use, 1975-2016: Volume II, College Students and Adults Ages 19-55, 1-445. Ann Arbor: Institute for Social Research, The University of Michigan. Retrieved from: http://monitoringthefuture.org/pubs.html\#monographs.

Sinha, J.W., Cnaan, R.A., \& Gelles, R.J. (2007). Adolescent risk behaviors and religion: findings from a national study. Journal of Adolescence, 30(2), 231-249.

Sobell, L.C., Ellingstad, T.P., \& Sobell, M.B. (2000). Natural recovery from alcohol and drug problems: methodological review of the research with suggestions for future directions. Addiction, 95(5), 749-764.

Stone, A.L., Becker, L.G., Huber, A.M., \& Catalano, R.F. (2012). Review of risk and protective factors of substance use and problem use in emerging adulthood. Addictive Behaviours, 37(7), 747-775.

Tillmann, M., \& Silcock, J. (1997). A comparison of smokers' and ex-smokers' healthrelated quality of life. Journal of Public Health, 19(3), 268-273.

Volkow, N.D., Baler, R.D., Compton, W.M., \& Susan, R.B. (2014). Adverse health effects of marijuana use. The New England Journal of Medicine, 370(23), 2219-2227.

von Sydow, K., Lieb, R., Pfister, H., Hofler, M., \& Wittchen, H.U. (2002). What predicts incident use of cannabis and progression to abuse and dependence? A 4-year prospective examination of risk factors in a community sample of adolescents and young adults. Drug and Alcohol Dependence, 68(1), 49-64. 
Whooley, M.A., Boyd, A.L., Gardin, J.M., \& Williams, D.R. (2002). Religious involvement and cigarette smoking in young adults. Archives of Internal Medicine, 162(14), 1604-1610.

Wills, T.A., Yaeger, A.M., \& Sandy, J.M. (2003). Buffering effect of religiosity for adolescent substance use. Psychology of Addictive Behaviors, 17(1), 24-31.

Wong, J., Lam, D.P., Abrishami, A., Chan, M.T.V., \& Chung, F. (2012). Short-term preoperative smoking cessation and postoperative complications: a systematic review and meta-analysis. Canadian Journal of Anesthesia, 59(3), 268-279.

Zanutto, E.L. (2006). A comparison of propensity score and linear regression analysis of complex survey data. Journal of Data Science, 4(1), 67-91. 
Table 1 Church attendance and substance non-use in the past 30 days

\begin{tabular}{|c|c|c|c|c|}
\hline & Cigarette & Alcohol & Marijuana & $\begin{array}{l}\text { Any illicit drugs } \\
\text { (including } \\
\text { marijuana) }\end{array}$ \\
\hline $\begin{array}{l}\text { Unadjusted } \\
\text { coefficient }\end{array}$ & $1.048(0.251)^{* * *}$ & $1.516(0.242)^{* * *}$ & $1.361(0.398)^{* *}$ & $1.495(0.397)^{* * *}$ \\
\hline $\begin{array}{l}\text { Adjusted } \\
\text { coefficient }\end{array}$ & $0.943(0.280)^{* *}$ & $1.426(0.275)^{* * *}$ & $1.277(0.423)^{* *}$ & $1.398(0.410)^{* *}$ \\
\hline ATT (kernel) & $0.203(0.058)^{* * *}$ & $0.174(0.051)^{* *}$ & $0.228(0.067)^{* *}$ & $0.251(0.065)^{* * *}$ \\
\hline Mean bias & 2.5 & 2.9 & 4.3 & 2.9 \\
\hline $\begin{array}{c}\text { ATT (nearest- } \\
\text { neighbour) }\end{array}$ & $0.158(0.066)^{*}$ & $0.191(0.056)^{* * *}$ & $0.200(0.081)^{*}$ & $0.239(0.085)^{* *}$ \\
\hline Mean bias & 7.6 & 8.6 & 8.1 & 6.1 \\
\hline $\mathbf{N}$ & 837 & 1045 & 668 & 684 \\
\hline
\end{tabular}

Notes: Unadjusted coefficients were obtained from logistic regression models that did not control for any covariates. Adjusted coefficients were obtained from logistic regression models that controlled for the covariates. ATT (kernel) presents ATT estimates from PSM models using Epanechnikov kernel matching with 0.05 bandwidths; the standard errors computed by bootstrapping with 1000 replications. ATT (nearest-neighbour) presents ATT estimates from PSM models matching with two neighbours; standard errors were computed using AbadieImbens formulas. Both PSM models controlled all covariates mentioned above, and common support condition was imposed.

Statistical significance is denoted by asterisks: 战 sig at $10 \%,{ }^{*}$ sig at $5 \%,{ }^{* *}$ sig at $1 \%,{ }^{* * *}$ sig at $0.1 \%$.

Success of the propensity score matching was assessed using a percentage bias of $<10 \%$ for each covariate. 
Table 2 Religious faith and substance non-use in the past $\mathbf{3 0}$ days

\begin{tabular}{cllll}
\hline & Cigarette & Alcohol & Marijuana & $\begin{array}{l}\text { Any illicit drugs } \\
\text { (including } \\
\text { marijuana) }\end{array}$ \\
\hline $\begin{array}{c}\text { Unadjusted } \\
\text { coefficient }\end{array}$ & $0.110(0.171)$ & $0.649(0.200)^{* *}$ & $0.152(0.160)$ & $0.175(0.157)$ \\
$\begin{array}{c}\text { Adjusted } \\
\text { coefficient }\end{array}$ & $0.149(0.189)$ & $0.480(0.232)^{*}$ & $0.104(0.182)$ & $0.102(0.175)$ \\
ATT (kernel) & $-0.005(0.036)$ & $0.055(0.023)^{*}$ & $-0.006(0.049)$ & $0.003(0.046)$ \\
Mean bias & 4.0 & 2.9 & 3.4 & 2.6 \\
ATT (nearest- & $-0.044(0.043)$ & $0.038(0.030)$ & $0.006(0.052)$ & $-0.004(0.053)$ \\
neighbour) & & 3.8 & & 3.7 \\
Mean bias & 4.3 & 1042 & 6.3 & 682 \\
N & 836 & 666 & & \\
\hline
\end{tabular}

Notes: Unadjusted coefficients were obtained from logistic regression models that did not control for any covariates. Adjusted coefficients were obtained from logistic regression models that controlled for the covariates. ATT (kernel) presents ATT estimates from PSM models using Epanechnikov kernel matching with 0.05 bandwidths; the standard errors computed by bootstrapping with 1000 replications. ATT (nearest-neighbour) presents ATT estimates from PSM models matching with two neighbours; standard errors were computed using AbadieImbens formulas. Both PSM models controlled all covariates mentioned above, and common support condition was imposed.

Statistical significance is denoted by asterisks: $\left\{\right.$ sig at $10 \%,{ }^{*}$ sig at $5 \%,{ }^{* *}$ sig at $1 \%,{ }^{* * *}$ sig at $0.1 \%$.

Success of the propensity score matching was assessed using a percentage bias of $<10 \%$ for each covariate. 


\begin{tabular}{|c|c|c|c|c|c|c|c|}
\hline & & & & Cigarette & Alcohol & Marijuana & $\begin{array}{l}\text { Any illicit drugs } \\
\text { (including } \\
\text { marijuana) }\end{array}$ \\
\hline \multirow[t]{6}{*}{1.} & \multirow{6}{*}{$\begin{array}{l}\text { Respondents with } \\
\text { problematic use at } \\
\text { Wave } 3\end{array}$} & Church & Kernel & $0.138(0.078)$ ↔ & $0.154(0.072)^{* \alpha}$ & $0.234(0.091)^{*}$ & $0.314(0.083)^{* * *}$ \\
\hline & & attendance & Nearest-neighbour & 0.130 (0.076)↔ & $0.154(0.088) \xi_{\alpha}$ & $0.190(0.111) \oiint^{\alpha}$ & $0.400(0.107)^{* * *}$ \\
\hline & & $\mathbf{N}$ & & 649 & 584 & 515 & 549 \\
\hline & & Religious & Kernel & $0.020(0.036)$ & $0.047(0.033)$ & $0.005(0.059)$ & $0.025(0.052)$ \\
\hline & & faith & Nearest-neighbour & $0.040(0.044)$ & $0.027(0.041)$ & $0.002(0.062)$ & $-0.009(0.062)$ \\
\hline & & $\mathbf{N}$ & & 648 & 582 & 513 & 547 \\
\hline \multirow[t]{6}{*}{2.} & \multirow{6}{*}{$\begin{array}{l}\text { Low levels of } \\
\text { attendance/religious } \\
\text { importance at Wave } \\
3\end{array}$} & Church & Kernel & $0.191(0.070)^{* *}$ & $0.210(0.060)^{* * *}$ & $0.226(0.074)^{* *}$ & $0.247(0.073)^{* *}$ \\
\hline & & attendance & Nearest-neighbour & $0.175(0.071)^{*}$ & $0.246(0.064)^{* * *}$ & $0.258(0.100)^{*}$ & $0.309(0.102)^{* *}$ \\
\hline & & $\mathbf{N}$ & & 773 & 947 & 623 & 639 \\
\hline & & Religious & Kernel & $0.016(0.052)$ & $0.071(0.035)^{*}$ & $0.012(0.067)$ & $0.031(0.070)$ \\
\hline & & faith & Nearest-neighbour & $0.041(0.067)$ & $0.058(0.041)$ & $0.000(0.070)$ & $-0.017(0.081)$ \\
\hline & & $\mathbf{N}$ & & 477 & 586 & 403 & 414 \\
\hline \multirow[t]{6}{*}{3.} & \multirow{6}{*}{$\begin{array}{l}\text { Substance non-use in } \\
\text { the past } 12 \text { months }\end{array}$} & Church & Kernel & - & $0.174(0.050)^{* *}$ & $0.256(0.077)^{* *}$ & $0.282(0.075)^{* * *}$ \\
\hline & & attendance & Nearest-neighbour & - & $0.216(0.056)^{* * *}$ & $0.020(0.085)^{*}$ & $0.272(0.093)^{* *}$ \\
\hline & & $\mathbf{N}$ & & & 1050 & 668 & 684 \\
\hline & & Religious & Kernel & - & $0.054(0.023)^{*}$ & $0.031(0.048)$ & $0.034(0.047)$ \\
\hline & & faith & Nearest-neighbour & - & $0.052(0.029) \rightsquigarrow$ & $0.039(0.055)$ & $0.044(0.053)$ \\
\hline & & $\mathbf{N}$ & & - & 1047 & 666 & 682 \\
\hline & $\begin{array}{l}\text { s: Information on cigar } \\
\text { sig at } 1 \%,{ }^{* * *} \text { sig at } \\
\text { marked with a }{ }^{\alpha} \text { signif } \\
\text { due to a lower sample }\end{array}$ & $\begin{array}{l}\text { tte use in the } \\
.1 \% \text {. Success } \\
\text { models whe }\end{array}$ & $\begin{array}{l}\text { st } 12 \text { months was } n \\
\text { the propensity scor } \\
\text { ese thresholds wer }\end{array}$ & $\begin{array}{l}\text { t available. Stat } \\
\text { matching was }\end{array}$ & $\begin{array}{l}\text { significance is d } \\
\text { ssed using a perc } \\
\text { the common sup }\end{array}$ & $\begin{array}{l}\text { ed by asterisks: } \\
\text { ge bias of }<10 \% \\
\text { area was too sm } \\
\text { ution. }\end{array}$ & $\begin{array}{l}\text { at } 10 \%,{ }^{*} \text { sig at } 5 \\
\text { each covariate. } \\
\text { produce efficient }\end{array}$ \\
\hline
\end{tabular}


Supplementary Table S1 Descriptive statistics for respondents who reported recent alcohol use in the Wave 3 interview by church attendance

\begin{tabular}{|c|c|c|}
\hline & $\begin{array}{l}\text { High attendance } \\
\text { (once a week or } \\
\text { more) }\end{array}$ & $\begin{array}{l}\text { Low attendance } \\
\text { (less than once a } \\
\text { week) }\end{array}$ \\
\hline & Mean (SD) or \% & Mean (SD) \\
\hline \multicolumn{3}{|l|}{ Wave 1} \\
\hline Age & $15.5(1.60)$ & $15.3(1.57)$ \\
\hline Female & 54.9 & 42.0 \\
\hline White & 68.6 & 79.8 \\
\hline African-American & 20.6 & 9.33 \\
\hline American-Indian/Asian/Mixed/Others & 10.8 & 10.9 \\
\hline Intact family & 65.7 & 64.4 \\
\hline Step-parents family & 9.80 & 12.8 \\
\hline Single-parent family & 24.5 & 22.8 \\
\hline Maternal high alcohol use ${ }^{1}$ & 17.7 & 30.3 \\
\hline Parental church attendance frequency ${ }^{2}$ & $3.25(0.97)$ & $2.69(1.14)$ \\
\hline [Parental] High school graduates or below & 33.3 & 33.1 \\
\hline $\begin{array}{l}\text { [Parental] completed a GED/vocational school } \\
\text { training }\end{array}$ & 32.4 & 32.7 \\
\hline [Parental] bachelor's degree or above & 34.3 & 34.3 \\
\hline Days of using alcohol in the past year ${ }^{3}$ & $2.30(2.55)$ & $2.62(2.51)$ \\
\hline Number of drinks each time in the past year & 2.46 (3.84); $\max =20$ & 3.01 (5.17); $\max =54$ \\
\hline \multicolumn{3}{|l|}{ Wave 3} \\
\hline Days of using alcohol in the past year & $3.85(0.80)$ & $3.95(0.85)$ \\
\hline Number of drinks each time in the past year & 5.95 (3.98); $\max =18$ & $5.97(3.52) ; \max =18$ \\
\hline \multicolumn{3}{|l|}{ Wave 4} \\
\hline High school graduates or below & 16.7 & 16.4 \\
\hline Completed a GED/vocational school training & 42.2 & 43.1 \\
\hline Bachelor's degree or above & 41.2 & 40.5 \\
\hline Married & 55.9 & 34.9 \\
\hline Cohabitation & 10.8 & 23.4 \\
\hline Single/legally separated & 33.3 & 41.7 \\
\hline Presence of child(ren) & 35.2 & 35.2 \\
\hline Living in rural/suburban & 63.3 & 69.6 \\
\hline Age at first drink ${ }^{4}$ & $16.1(2.95)$ & $15.4(2.67)$ \\
\hline Alcohol non-use in the past 30 days & 31.4 & 9.12 \\
\hline Total $\mathbf{N}$ & 102 & 943 \\
\hline \multicolumn{3}{|c|}{$\begin{array}{l}\text { Note: }{ }^{1} \text { Consumed more than } 2 \text { or } 3 \text { alcoholic drinks per month. }{ }^{2} \mathrm{~A} \text { four-point scale, ranging from } \\
\text { "never", "less than once a month", "less than once a week, but at least once a month", to } \\
\text { "once a week or more". }{ }^{3} \mathrm{~A} \text { seven-point scale, ranging from "none", " } 1 \text { or } 2 \text { days in the past } \\
12 \text { months", "once a month or less", " } 2 \text { or } 3 \text { days a month", " } 1 \text { or } 2 \text { days a week", "3-5 days } \\
\text { a week", to "every day/almost every day". }{ }^{4} \text { A continuous indicator derived from responses } \\
\text { to all waves; the age reported at the earlier wave was used to reduce recall error. }\end{array}$} \\
\hline
\end{tabular}


Supplementary Table S2 Descriptive statistics for respondents who reported recent alcohol use in the Wave 3 interview by religious faith

\begin{tabular}{|c|c|c|}
\hline & $\begin{array}{l}\text { Very } \\
\text { important/most } \\
\text { important }\end{array}$ & $\begin{array}{l}\text { Somewhat } \\
\text { important/not } \\
\text { important }\end{array}$ \\
\hline & Mean (SD) or \% & Mean (SD) \\
\hline \multicolumn{3}{|l|}{ Wave 1} \\
\hline Age & $15.3(1.61)$ & $15.3(1.55)$ \\
\hline Female & 46.5 & 40.7 \\
\hline White & 71.3 & 85.1 \\
\hline African-American & 18.0 & 3.94 \\
\hline American-Indian/Asian/Mixed/Others & 10.7 & 10.9 \\
\hline Intact family & 63.4 & 65.4 \\
\hline Step-parents family & 12.8 & 12.4 \\
\hline Single-parent family & 23.8 & 22.2 \\
\hline Maternal high alcohol use ${ }^{1}$ & 23.3 & 34.1 \\
\hline Parental religions importance ${ }^{2}$ & $3.66(0.68)$ & $3.18(0.96)$ \\
\hline [Parental] High school graduates or below & 33.1 & 33.2 \\
\hline $\begin{array}{l}\text { [Parental] completed a GED/vocational school } \\
\text { training }\end{array}$ & 35.3 & 30.3 \\
\hline [Parental] bachelor's degree or above & 31.6 & 36.6 \\
\hline Days of using alcohol in the past year ${ }^{3}$ & $2.37(2.55)$ & $2.78(2.46)$ \\
\hline \multicolumn{3}{|l|}{ Wave 3} \\
\hline Days of using alcohol in the past year & $3.85(0.82)$ & $4.01(0.86)$ \\
\hline Number of drinks each time in the past year & 6.09 (3.88); $\max =18$ & 5.87 (3.27); $\max =18$ \\
\hline \multicolumn{3}{|l|}{ Wave 4} \\
\hline High school graduates or below & 15.7 & 17.2 \\
\hline Completed a GED/vocational school training & 44.6 & 41.6 \\
\hline Bachelor's degree or above & 39.7 & 41.2 \\
\hline Married & 42.2 & 32.6 \\
\hline Cohabitation & 16.7 & 27.1 \\
\hline Single/legally separated & 41.1 & 40.3 \\
\hline Presence of child(ren) & 43.2 & 32.1 \\
\hline Living in rural/suburban & 64.9 & 63.1 \\
\hline Age at first drink ${ }^{4}$ & $15.7(2.75)$ & $15.3(2.66)$ \\
\hline Alcohol non-use in the past 30 days & 14.7 & 8.24 \\
\hline Total N & 484 & 558 \\
\hline \multicolumn{3}{|c|}{$\begin{array}{l}\text { Note: }{ }^{1} \text { Consumed more than } 2 \text { or } 3 \text { alcoholic drinks per month. }{ }^{2} \mathrm{~A} \text { four-point scale, ranging from } \\
\text { "not important at all", fairly unimportance", "fairly important", to "very important". }{ }^{3} \mathrm{~A} \\
\text { seven-point scale, ranging from "none", " } 1 \text { or } 2 \text { days in the past } 12 \text { months", "once a month } \\
\text { or less", " } 2 \text { or } 3 \text { days a month", " } 1 \text { or } 2 \text { days a week", " } 3-5 \text { days a week", to "every } \\
\text { day/almost every day". }{ }^{4} \mathrm{~A} \text { continuous indicator derived from responses to all waves; the } \\
\text { age reported at the earlier wave was used to reduce recall error. }\end{array}$} \\
\hline
\end{tabular}

